\title{
The presence of stromal mast cells identifies a subset of invasive breast cancers with a favorable prognosis
}

\author{
Shahriar Dabiri ${ }^{1, *}$, David Huntsman ${ }^{1,2}$, Nikita Makretsov $^{2}$, Maggie Cheang $^{2}$, Blake Gilks ${ }^{2}$, \\ Chris Badjik ${ }^{3}$, Karen Gelmon ${ }^{4}$, Stephen Chia ${ }^{4}$ and Malcolm Hayes ${ }^{1}$ \\ ${ }^{1}$ Department of Pathology, British Columbia Cancer Agency, Vancouver, BC, Canada; ${ }^{2}$ Genetic Pathology \\ Evaluation Centre of Department of Pathology and Prostate Research Centre, Vancouver General Hospital, \\ Vancouver, BC, Canada; ${ }^{3}$ Department of Epidemiology, British Columbia Cancer Agency, Vancouver, BC, \\ Canada and ${ }^{4}$ Department of Medical Oncology, British Columbia Cancer Agency, Vancouver, BC, \\ Canada
}

\begin{abstract}
Tissue microarrays containing 348 cases of invasive breast carcinoma were studied by immunohistochemical staining for CD-117, CD-3, CD-20, CD-68, Her2, estrogen receptor protein, and progesterone receptor protein, and results were correlated with patient outcome. Hormone receptor status (both estrogen receptor and progesterone receptor) correlated with a good outcome while Her2 overexpression was associated with a poor outcome. The presence of mast cells in the stroma, as demonstrated by positive c-kit (CD-117) staining, correlated with a good prognosis $(P=0.0036)$. On subset analysis, this association between the presence of mast cells and favorable prognosis was present in the node-negative patients $(P=0.018)$. The presence of mast cells showed an inverse correlation with the presence of CD-68 positive macrophages. No correlation was observed between the presence of mast cells and either B-cells (CD20-positive) or T-cells (CD3-positive). The presence of stromal mast cells was of prognostic significance independent of nodal status and tumor size $(P=0.02)$. When the multivariate analysis was expanded to include tumor grade, estrogen receptor status and Her2 status, as well as tumor size and nodal status, the presence of stromal mast cells approached significance as an independent prognostic indicator.

Modern Pathology (2004) 17, 690-695, advance online publication, 26 March 2004; doi:10.1038/modpathol.3800094
\end{abstract}

Keywords: CD-117; c-kit; mast cells; immunostaining; prognosis

Previous studies of mast cells in invasive breast carcinoma have suggested that the presence of mast cells in the peritumoral stroma is associated with a favorable prognosis. ${ }^{1-4}$ It has further been suggested that this association is due to a correlation between mast cell infiltrates and low tumor grade. ${ }^{4} \mathrm{c}$-kit is a transmembrane tyrosine kinase receptor protein, which is expressed by hematological stem cells, germ cells, melanocytes, and interstitial cells of Cajal, and by both normal and neoplastic mast cells. ${ }^{5-7}$ We used immunostaining for c-kit (CD-117) to identify mast cells in the stroma of invasive breast

Correspondence: Dr M Hayes, Department of Pathology, British Columbia Cancer Agency, 600 West 10th Avenue, Vancouver, BC, Canada V5Z 4E6.

E-mail: mhayes@bccancer.bc.ca

${ }^{*}$ Dr S Dabiri is a visiting Professor of Pathology from the University of Kerman, Iran.

Received 16 October 2003; revised 26 January 2004; accepted 28 January 2004; published online 19 March 2004 carcinomas, using tissue microarrays containing 348 cases with clinical follow-up data, to determine whether the presence of stromal mast cells was of prognostic significance in this large cohort of patients. Immunostains for T- and B-lymphocytes and histiocytes were also assessed on the same tissue microarrays to determine whether there was a correlation between the presence of mast cells and other inflammatory cells. Finally, the relationship between the presence of mast cells and other established prognostic markers, including hormone receptor expression, Her2 status, grade, and lymph node status, was assessed.

\section{Materials and methods}

Prior to initiating the study, the ethics committee of the University of British Columbia approved this project. All cases of breast cancers were retrieved from the pathology archives of Vancouver General 
Hospital for the years 1975-1995. Tissue microarrays were constructed from 348 cases of invasive breast carcinoma identified. All patients were diagnosed at Vancouver General Hospital and treated at the British Columbia Cancer Agency according to provincial treatment guidelines. Follow-up data were available on all 348 patients for 627 years after diagnosis median follow-up time 14.7 years. For purposes of survival analysis, 20 years was used as the cut-off time. The $\mathrm{H} \& \mathrm{E}$ stained slides from each case were reviewed and the tumors graded independently according to the Nottingham modification of the Scarth Bloom Richardson method ${ }^{8}$ by two pathologists (SD and $\mathrm{MH}$ ). A representative sample of the invasive component of each breast carcinoma was selected and two $0.6 \mathrm{~mm}$ cores were removed and transferred into a recipient microarray block as described previously ${ }^{9}$. There was no attempt to select areas based on the presence of inflammation or any particular growth pattern. The tissue arrays were sectioned and stained with antibodies to CD-117, CD-3, CD-20, CD-68, Her2, estrogen receptor (ER), and progesterone receptor (PR) using standard immunoperoxidase techniques (Table 1). The Envision detection system (DAKO) was used to detect the primary antibodies. The number of positively immunostaining cells in the peritumoral stroma was assessed using a simple scoring system for each antibody as follows: CD-117: no mast cells $=0$, any mast cells $=1$; CD-3, CD-20, CD-43, and CD-68: $<10$ positive cells/core $=0, \geq 10$ positive cells/core $=1$. Staining for ER and PR was scored according to the method of Reiner et $a l^{10}$ : $<10 \%$ of nuclei stained $=0, \geq 10 \%$ of nuclei stained $=1$. Her2 staining was scored according to the criteria used for Herceptest: Herceptest 0 or $1+=0$, Herceptest 2 or $3+=1$. Scoring was performed independently by two pathologists and any discrepancies were resolved over a double-head microscope (SD and $\mathrm{MH}$ ). Scoring was done without a knowledge of patient outcomes. Cores that failed to contain invasive carcinoma, and those that had lifted off the slide during immunostaining were not scored. Results were correlated with nodal status, grade of the tumor, and patient outcome. Spearman's nonparametric two-tailed correlation test was used for correlative analysis. Breast cancer specific survival was analyzed by the Kaplan-Meier method. The log-rank test was used to assess differences between curves. Correction was made for multiple comparisons. Multivariate analysis was performed using the Cox proportional hazard model, and a confidential interval of $95 \%$ was chosen. SPSS software (v. 11) was used for all statistical analyses.

\section{Results}

The age of the patients at the time of diagnosis ranged from 28.2 to 87.3 years (median 63 years) and was distributed normally. Tumor size was less than or equal to $20 \mathrm{~mm}$ in 162 cases, greater than $20 \mathrm{~mm}$ in 126 cases, and not known in 60 cases. In all, 110 patients had positive axillary lymph nodes, 199 had negative nodes, and the nodal status was not known in 39 cases.

Management varied based on the year of diagnosis; however, analysis confirmed the expected prognostic significance of ER status $(P=0.0084), \mathrm{PR}$ status $(P=0.0092)$, and Her2 status $(P=0.0238)$ of the tumors. Tumor size greater than $20 \mathrm{~mm}$ and the presence of lymph node metastasis correlated strongly with poor outcome $(P<0.0001)$, while tumor grade did not reach significance $(P=0.08)$. The previously well-documented positive correlation between ER and PR status was demonstrated, as was the negative association between hormone receptor protein expression (either ER or PR) and Her2 positivity (Table 2). c-kit-positive mast cells were detected in the stroma of 93 of the 348 cases (Figure 1).

None of the cases showed c-kit positivity in breast carcinoma cells. In all, 28 of 110 cancers in the node-positive group, 60 of 199 cancers in the nodenegative group, and five of 39 cases in the nodal status unknown group contained mast cells, a statistically insignificant difference $(P=0.3)$. Kaplan-Meier survival curves showed a strong correlation between the presence of mast cells and a favorable prognosis $(P<0.0036)$ (Figure 2). This effect was also observed in node-negative cancers $(P=0.0177)$ but not node-positive cancers $(P=0.384)$. There was a negative correlation between the presence of mast cells and infiltration of the tumors by CD-68-positive cells and tumor size. There was no correlation between the presence of mast cells and CD-43, CD-20, and CD-3 positive cells. There was a positive association between the

Table 1 Antibodies used for immunohistochemical staining

\begin{tabular}{lllll}
\hline Antibody & Source & Dilution & Cell type stained & Antigen retrieval \\
\hline c-kit & Dako & $1: 50$ & Mast cells & None \\
CD-3 & Novocastra & $1: 600$ & T-lymphocytes & Decloak 5 min EDTA \\
CD-20 & Dako & $1: 500$ & B-lymphocytes & $0.05 \%$ pronase \\
CD-68 & Dako & $1: 800$ & Macrophages & Decloak 5 min TRS \\
ER & Dako & $1: 100$ & Breast & Steam 20 min EDTA \\
Her2 A485 & Dako & $1: 500$ & Breast & Steam 20 min TRS \\
PR & Dako & $1: 100$ & Breast & Steam 20 min EDTA
\end{tabular}




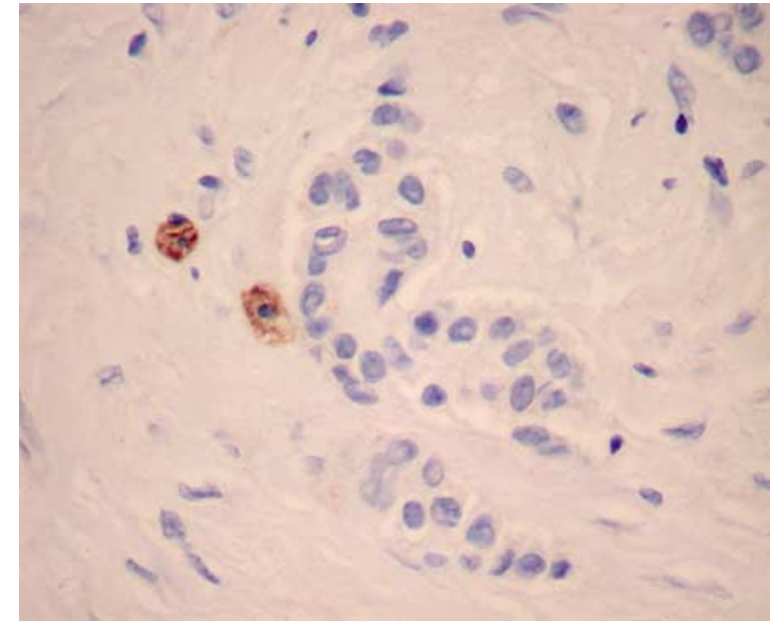

Figure 1 Mast cells in the stroma adjacent to invasive breast carcinoma (immunoperoxidase stain for c-kit).

presence of CD-68-positive cells and the presence of B- or T-lymphocytes. The presence of mast cells showed no correlation with the ER, PR, or Her2 status. There was no correlation between the presence of mast cells and tumor grade (Table 2).

In multivariate analysis, the presence of stromal mast cells was a significant prognostic factor $(P=0.02)$ independent of nodal status or tumor size. When the presence of stromal mast cells was compared to other histopathological parameters (tumor grade, ER status, Her2 status) it was of independent significance $(P=0.03)$. When the analysis was extended to include all clinical and pathological parameters, the presence of stromal mast cells was of borderline significance $(P=0.06)$ (Table 3).

\section{Discussion}

Aaltomaa et $a l^{4}$ showed that the presence of numerous stromal mast cells was associated with a good prognosis, and also observed a correlation between stromal mast cells and small size of the tumor, tubular differentiation, and hormone receptor expression. While we confirmed the favorable prognostic significance of stromal mast cells in a larger patient cohort, we did not see a significant relationship between mast cell infiltrates and grade of the tumor or hormone-receptor status in the present study. Mast cell infiltration of peritumoral stroma correlated negatively with tumor size, and in multivariate analysis retained independent prognostic significance from this parameter. We have further established that the presence of stromal mast cells is independent of the presence of B- and T- lymphocytes; thus, the prognostic significance of stromal mast cells is not a reflection of a generic immune response to the tumors. 

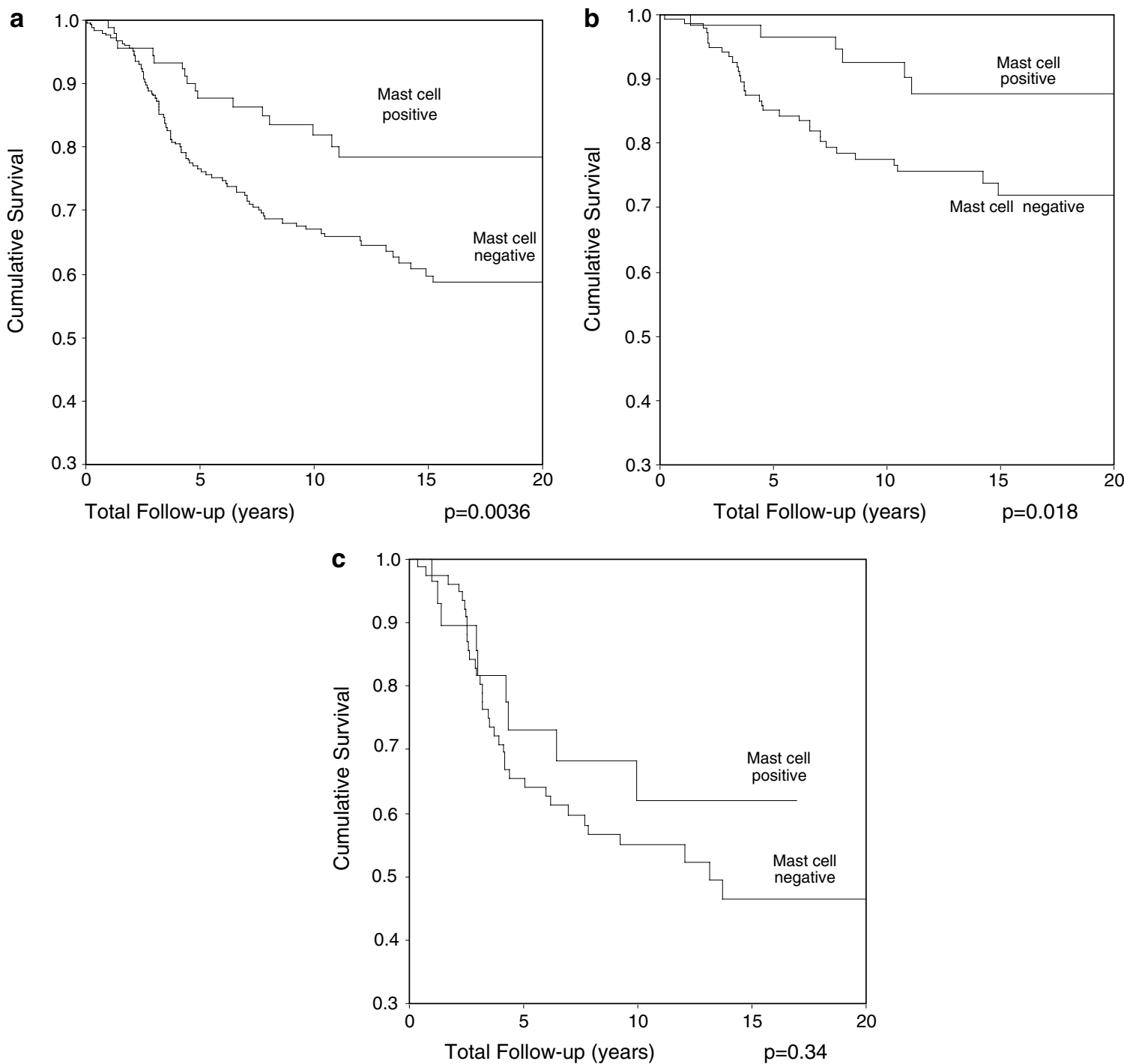

Figure 2 Disease specific survival for patients with and without stromal mast cells: (a) all patients; (b) node-negative cases; (c) nodepositive cases.

Table 3 Multivariate analysis

\begin{tabular}{|c|c|c|c|}
\hline Model & Markers & $P$-value (95\% C.I.) & Relative risk \\
\hline \multirow[t]{3}{*}{ SMC and clinical parameters } & SMC & 0.02 & $0.38(0.17-0.86)$ \\
\hline & Nodal status & 0.003 & $2.65(1.4-4.98)$ \\
\hline & Tumor size & 0.22 & $1.48(0.79-2.76)$ \\
\hline \multirow[t]{4}{*}{ SMC and histopathological parameters } & SMC & 0.03 & $0.5(0.28-0.94)$ \\
\hline & Grade & 0.41 & $0.85(0.59-1.24)$ \\
\hline & ER & 0.03 & $0.76(0.59-0.97)$ \\
\hline & Her2 & 0.45 & $1.29(0.66-2.51)$ \\
\hline \multirow[t]{6}{*}{ SMC and all variables (clinical and histopathological) } & SMC & 0.06 & $0.32(0.09-1.06)$ \\
\hline & Nodal status & 0.01 & $2.41(1.21-4.79)$ \\
\hline & Tumor size & 0.68 & $1.16(0.57-2.36)$ \\
\hline & Grade & 0.32 & $0.78(0.47-1.28)$ \\
\hline & ER & 0.055 & $0.7(0.48-1)$ \\
\hline & Her2 & 0.22 & $1.8(0.71-4.6)$ \\
\hline
\end{tabular}

SMC: stromal mast cells, identified by c-kit staining; C.I: confidence interval.

Quantification of the host immune response to tumor is technically problematic. By using tissue microarrays and a specific and sensitive immuno- histochemical method to demonstrate mast cells, we were able to divide our patient population into those whose tumors contained no mast cells vs tumors 
with one or more mast cells $/ 0.57 \mathrm{~mm}^{2}$ of tumor (the area of tumor contained in two $0.6 \mathrm{~mm}$ cores). Although this is an arbitrary cut-off, it serves to demonstrate the prognostic significance of stromal mast cells, is much less labor intensive than morphometric methods for quantifying mast cells and, importantly, is easily reproducible for future tissue microarray studies. Ultimately, the utility of a prognostic indicator is limited if it does not influence patient management. Current treatment guidelines recommend adjuvant treatment for $90 \%$ of patients with node-negative disease, even though only $30 \%$ will relapse, and will therefore stand to benefit from adjuvant therapy. ${ }^{11}$ In the case of stromal mast cell assessment, its prognostic significance in node-negative breast cancers is promising, for in this group of patients with a generally favorable prognosis, identification of markers of decreased risk of death could be used to identify a subgroup of patients with a sufficiently favorable prognosis that adjuvant chemotherapy is not indicated.

A mechansitic understanding of the relationship between stromal mast cells and improved patient outcome may prove more important than any role for mast cell assessment as a prognostic marker. Mast cells produce a large number of amines, such as histamine, enzymes including tryptase and chymase, and cell activator molecules, such as the cytokine interleukin-4, that might influence the ability of breast carcinoma cells to invade and metastasize. ${ }^{12}$ It is possible, for example, that interleukin-4 produced by mast cells could induce apoptosis of breast cancer cells, so diminishing the rate of growth and metastatic potential of breast carcinoma. ${ }^{13}$ Histamine has been shown to promote the growth of breast carcinoma cells in vitro. ${ }^{14}$ Although both $\mathrm{H}-1$ and $\mathrm{H}-2$ receptors are present on benign breast epithelial cells, $\mathrm{H}-2$ receptors are absent on the cell surface of many breast carcinomas and administration of the $\mathrm{H}-2$ receptor antagonist cimetidine did not influence the proliferation rate of breast carcinomas as assessed by MIB-1 immunostaining. ${ }^{15}$ An immunosuppressive role for mast cells in breast cancer, mediated via histamine, has also been postulated. ${ }^{16}$ A negative correlation between the number of mast cells present in regional lymph nodes and the presence of breast cancer metastases has been noted, ${ }^{17}$ which further suggests a potential inhibitory role for mast cells on tumor growth. This concept has been supported by recent studies in a rat model of breast carcinoma. ${ }^{18}$

The role of c-kit (CD-117) in breast carcinoma is poorly understood. Some studies have shown that ckit protein is present in normal breast tissue but is absent in female, but not male, breast carcinoma, ${ }^{19,20}$ and loss of c-kit expression has been postulated as having a role in the development of breast carcinoma..$^{21,22}$ In contrast, Palmu et $a l^{23}$ found that a high percentage of poor-prognosis breast cancers stain for CD-117 by immunohistochemistry. The variability in c-kit immunostaining reported in the literature most probably reflects differing sensitivities in different laboratories. With our immunohistochemical technique, we did not observe c-kit expression in breast carcinoma cells in any case.

Tissue microarray technology is a useful tool to investigate the significance of prognostic and predictive markers in large patient cohorts, ${ }^{24,25}$ and the validity of our array of 348 cases of invasive breast cancer is confirmed by the expected correlation between ER, PR, and Her2 expression with patient outcome. This study shows that the presence of mast cells in the peritumoral stroma correlates with a good prognosis in breast cancers with long-term follow-up, particularly in the node-negative subset, supporting a biologically important role for host mast cells in breast cancer.

\section{Acknowledgements}

DH is a scholar of the Michael Smith Foundation for Health Research, and NM was supported in part by an educational grant from Aventis Canada.

\section{References}

1 Syrjanen KJ, Hjelt LH. Tumor-host interrelationships in carcinoma of the female breast. Surg Gynecol Obstet 1978;147:43-48.

2 Hartveit F. Mast cells and metachromasia in human breast cancer: their occurrence, significance and consequence: a preliminary report. J Pathol 1981;134:7-11.

3 Fisher ER, Sass R, Watkins G, et al. Tissue mast cells in breast cancer. Breast Cancer Res Treat 1985;5:285-291.

4 Aaltomaa S, Lipponen P, Papinaho S, et al. Mast cells in breast cancer. Anticancer Res 1993;13:785-788.

5 Baek JY, Tefferi A, Pardanani A, et al. Immunohistochemical studies of c-kit, transforming growth factorbeta, and basic fibroblastic growth factor in mast cell disease. Leuk Res 2002;26:83-90.

6 Gibson PC, Cooper K. CD-117 (KIT): a diverse protein with selective applications in surgical pathology. Adv Anat Pathol 2002;9:65-69.

7 Fletcher CDM, Fletcher JA. Testing for KIT (CD-117) in gastrointestinal stromal tumors: another HercepTest? Am J Clin Pathol 2002;118:163-164.

8 Elston C W, Ellis IO. Pathological prognostic factors in breast cancer. I. The value of histological grade in breast cancer: experience from a large study with longterm follow-up. Histopathology 1991;19:403-410.

9 Parker RL, Huntsman DG, Lesack DW, et al. Assessment of interlaboratory variation in the immunohistochemical determination of estrogen receptor using a breast cancer tissue microarray. Am J Clin Pathol 2002;117:723-728.

10 Reiner A, Neumeister B, Spona J, et al. Immunocytochemical localization of estrogen and progesterone receptor and prognosis in human primary breast cancer. Cancer Res 1990;50:7057-7061.

11 Goldhirsch A, Glick JH, Gelber RD, et al. Meeting highlights: International consensus panel on the 
treatement of primary breast cancer. J Clin Oncol 2001;19:3817-3827.

12 Metcalfe DD, Baram D, Mekori YA. Mast Cells. Physiol Rev 1997;77:1033-1079.

13 Gooch JL, Lee AV, Yee D. Interleukin 4 inhibits growth and induces apoptosis in human breast cancer cells. Cancer Res 1998;58:4199-4205.

14 Cricco GP, Davio CA, Martin G, et al. Histamine as an autocrine growth factor in experimental mammary carcinomas. Agents Actions 1994;43:17-20.

15 Bowrey PF, King J, Magarey C, et al. Histamine, mast cells and tumor cell proliferation in breast cancer: does preoperative cimetidine administration have an effect? Br J Cancer 2000;82:167-170.

16 Reynolds JL, Akhter JA, Margarey CJ, et al. Histamine in human breast cancer. Br J Surg 1998;85:538-541.

17 Naik R, Pai MR. Mast cell numbers in lymph node lesions. Indian J Pathol Microbiol 1998;41:153-156.

18 Quan C, Wang H, Lu S. Resistance to mammary carcinogenesis in Copenhagen rats: potential roles of vascular endothelial growth factor and mast cells. Cancer Lett 2002;186:165.

19 Tsuura Y, Hiraki H, Watanabe K, et al. Preferential localization of c-kit product in tissue mast cells, basal cells of the skin, epithelial cells of breast, small cell lung carcinoma and seminoma/dysgerminoma in human: immunohistochemical study on formalin-fixed, paraffin-embedded tissues. Vichows Arch 1994;424: 135-141.

20 Tsuura Y, Suzuki T, Honma K, et al. Expression of c-kit protein in proliferative lesions of human breast: sexual difference and close association with phosphotyrosine status. J Cancer Res Clin Oncol 2002;128:239-246.

21 Natali PG, Nicotra MR, Sures I, et al. Breast cancer is associated with loss of the c-kit oncogene product. In J Cancer 1992;52:713-717.

22 Chui X, Egami H, Yamashita J, et al. Immunohistochemical expression of the c-kit proto-oncogene product in human malignant and non-malignant breast tissues. Br J Cancer 1996;73:1233-1236.

23 Palmu S, Soderstrom KO, Quazi K, et al. Expression of c-kit and HER2 tyrosine kinase receptors in poorprognosis breast cancer. Anticancer Res 2002;22: 411-414.

24 Kononen J, Bubendorf L, Kallioniemi A, et al. Tissue Microarray for high-throughput molecular profiling of tumor specimens. Nature Med 1998;4:844-847.

25 Torhorst J, Bucher C, Kononen J, et al. Tissue microarrays for rapid linking of molecular changes to clinical endpoints. Am J Pathol 2001;159:2249-2256. 